\title{
Prevalence of Thinness, Overweight, Obesity, and Central Obesity in Finnish School-Aged Children: A Comparison of National and International Reference Values
}

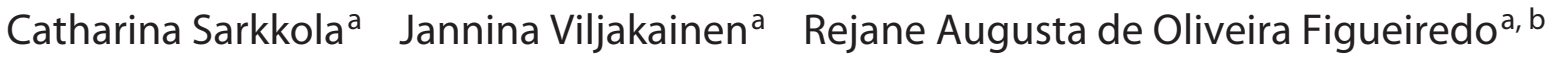

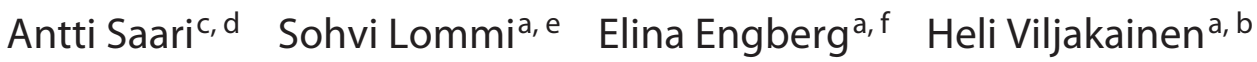 \\ ${ }^{a}$ Folkhälsan Research Center, Helsinki, Finland; ${ }^{b}$ Faculty of Medicine, University of Helsinki, Helsinki, Finland; ${ }^{c}$ Kuopio \\ University Hospital, Kuopio, Finland; 'University of Eastern Finland, Kuopio, Finland; 'Department of Public Health, Faculty \\ of Medicine, University of Helsinki, Helsinki, Finland; fDepartment of Psychology and Logopedics, Faculty of Medicine, \\ University of Helsinki, Helsinki, Finland
}

\section{Keywords}

Children · Body mass index · Reference values · Overweight ·

Central obesity

\begin{abstract}
Introduction: The global epidemic of obesity concerns children, and monitoring the prevalence is of highest priority. Body mass index (BMI) with age- and sex-specific cutoff values determines weight status in children, although multiple reference systems exist. Our aim was to compare the prevalence for thinness, normal weight, overweight, and obesity in Finnish school-aged children according to national and international reference values, as well as to determine which cutoff values for overweight agree with the criteria for central obesity. Methods: This study includes 10,646 children aged 9-12 years from the Finnish Health in Teens cohort. Height, weight, and waist circumference were measured in 2011-2014. BMI (weight $[\mathrm{kg}] /$ height $[\mathrm{m}]^{2}$ ) and the waist-toheight ratio (WHtR; waist $[\mathrm{cm}] /$ height $[\mathrm{cm}]$ ) were calculated. The WHtR cutoff of $>0.5$ indicated central obesity. We compared the sex-specific prevalence of thinness, overweight,
\end{abstract}

and obesity using the International Obesity Task Force (IOTF), World Health Organization (WHO) and Finnish (FIN) $\mathrm{BMI}$-for-age reference values, as well as these three against central obesity based on the WHtR. Results: The prevalence of thinness, overweight, and obesity were $11.0 \%, 12.7 \%$, and $2.6 \%$, respectively, using IOTF; $2.6 \%, 15.9 \%$, and $5.2 \%$ using WHO; and $5.1 \%, 11.4 \%$, and $2.2 \%$ using FIN. Overweight and obesity were more common in boys than girls using WHO and FIN, while thinness was more common in girls using IOTF and FIN. IOTF versus WHO exhibited moderate agreement ( $\mathrm{K}$ $=0.59)$, which improved for IOTF versus FIN $(\mathrm{K}=0.74)$. Of those classified as overweight by $\mathrm{WHO}, 37 \%$ and $47 \%$ were regarded as normal weight according to IOTF and FIN, respectively. The prevalence of central obesity was $8.7 \%$, and it was more common in boys than girls. WHO provided the highest sensitivity: $95 \%$ of individuals with central obesity were classified with overweight or obesity. Using FIN provided the highest specificity (93\%). Conclusion: Our findings show that WHO overestimates the prevalence of overweight

Jannina Viljakainen and Rejane Augusta de Oliveira Figueiredo shared authorship.
(C) 2021 The Author(s)

Published by S. Karger AG, Basel

This is an Open Access article licensed under the Creative Commons Attribution-NonCommercial-4.0 International License (CC BY-NC) (http://www.karger.com/Services/OpenAccessLicense), applicable to the online version of the article only. Usage and distribution for commercial purposes requires written permission.
Correspondence to:

Heli Viljakainen, heli.viljakainen@helsinki.fi 
and obesity, while IOTF overrates thinness. Thus, comparing prevalence rates between studies requires caution. The novelty of this study is the comparison of the cutoff values for overweight with central obesity. The choice of reference system affects the generalizability of the research results.

(C) 2021 The Author(s)

Published by S. Karger AG, Basel

\section{Introduction}

Childhood obesity is one of the most serious public health challenges. The prevalence of overweight and obesity among children has increased globally in recent decades, although that increase has leveled in many highincome countries [1].

In order to assess the prevalence of overweight and obesity, objective measurements of body size and shape are needed. Anthropometric measures such as height, weight, and waist circumference resulting in body mass index (BMI) and the waist-to-height ratio (WHtR) are often used in epidemiological research. BMI is a widely used measurement to determine weight status in children. However, adult cutoff values for BMI cannot be directly applied to children. Age- and sex-specific cutoff values are therefore generated, which correspond with a BMI of 25 (for overweight); 30 (for obesity); and 18.5, 17, and 16 (for thinness grades 1,2 , and 3 ) at the age of 18 years, often referred to as BMI-for-age or BMI $z$-scores. The cutoff values for children consider growth at different ages and for both sexes. The child curves are drawn so that they pass the abovementioned, widely used adult cutoffs at the age of 18 years.

Two international datasets are used to classify thinness, normal weight, overweight, and obesity in children based on BMI: the International Obesity Task Force (IOTF) $[2,3]$ and the World Health Organization (WHO) [4] reference values. The IOTF reference system relies on BMI data from six large, nationally representative crosssectional surveys from Great Britain, the Netherlands, Hong Kong, Singapore, Brazil, and the USA [2]. Using data collected between 1963 and 1993, the total sample size reached approximately 190,000 individuals aged 0-25 years. The 2007 WHO growth reference [4] combines two reference values which includes 5-19 year olds: data from the 1977 National Center for Health Statistics/ WHO international growth reference (1-24 years) [5] and the WHO Child Growth Standards (18-71 months) [6], comprising a total of approximately 30,000 individuals. The latter dataset originates from Norway, Ghana, Oman, India, Brazil, and the USA collected between 1997 and 2003. Growth patterns depend on genetics and the environment, rendering national, local reference values also necessary. The Finnish BMI-for-age reference values (FIN) are based on a combination of cross-sectional and longitudinal data from more than 73,000 healthy subjects aged 0-20 years [7]. Data were collected between 2003 and 2009.

In general, a higher prevalence of overweight and obesity has been observed using WHO rather than IOTF reference values in children from various countries across Europe [8-16], North America and Asia [3], South America $[17,18]$, and Africa [19]. Yet, opposing findings were reported in two Iranian studies [20, 21]. The reference values applied seem to also affect the prevalence of thinness. Some studies reported higher rates using IOTF rather than WHO reference values [13, 21-23], but opposing results have also been reported $[3,10,12,16]$.

Furthermore, the WHtR has gained attention as a measure of central obesity in children [24, 25]. The WHtR may carry an advantage over BMI, which does not provide information about body fat distribution or body shape. In addition, the WHtR is considered a more reliable predictor of cardiovascular disease risk in children than BMI [26]. The WHtR is only weakly associated with age. Thus, the same cutoff value of 0.5 for central obesity has been suggested as useful across all age-groups in children $[27,28]$. In German adolescents, a fixed cutoff of 0.5 agreed well with the age- and sex-specific 90th percentile for the WHtR [29]. Population-specific references and age- and sex-specific cutoff values are therefore not necessary, in contrast to BMI.

Our primary objective in this study was to compare the sex-specific prevalence for thinness, normal weight, overweight, and obesity in Finnish school-aged children according to IOTF, WHO, and FIN BMI-for-age reference values. The secondary objective was to describe the prevalence of central obesity based on the WHtR and to determine which cutoff values for overweight agree with the criteria for central obesity.

\section{Materials and Methods}

\section{Study Population}

This cross-sectional study utilizes data from the Finnish Health in Teens (Fin-HIT) study [30], collected between 2011 and 2014. The total cohort consists of 11,407 children aged 9-12 years from across Finland. The majority of the children participated in the study through schools in Finland's largest cities and their surrounding areas: Helsinki, Espoo, Vantaa, Turku, Tampere, Jyväskylä, Kuopio, and Oulu. Here, we focus on 10,646 children for whom data are available on age, sex, height, and weight. Data on 
Table 1. The Fin-HIT cohort: characteristics for all children and based on sex, reported as mean (SD), unless otherwise indicated

\begin{tabular}{|c|c|c|c|c|}
\hline & All & Girls & Boys & $p$ value \\
\hline Participants, $n(\%)$ & 10,646 & $5,594(52.5)$ & $5,052(47.5)$ & \\
\hline Age, years & $11.2(0.8)$ & $11.1(0.9)$ & $11.2(0.8)$ & $0.35^{\mathrm{a}}$ \\
\hline Height, cm & $147.7(8.6)$ & $147.8(8.8)$ & $147.6(8.3)$ & $0.23^{a}$ \\
\hline Weight, kg & $39.4(9.2)$ & $39.4(9.2)$ & $39.5(9.3)$ & $0.63^{a}$ \\
\hline $\mathrm{BMI}, \mathrm{kg} / \mathrm{m}^{2}$ & $17.9(2.9)$ & $17.8(2.9)$ & $17.9(2.9)$ & $0.08^{\mathrm{a}}$ \\
\hline BMI z-score, IOTFb & $0.22(1.00)$ & $0.17(0.99)$ & $0.27(1.00)$ & $<0.001^{\mathrm{a}}$ \\
\hline BMI z-score, $\mathrm{WHO}^{\mathrm{c}}$ & $0.09(1.13)$ & $-0.002(1.09)$ & $0.18(1.17)$ & $<0.001^{\mathrm{a}}$ \\
\hline BMI z-score, FIN ${ }^{d}$ & $-0.16(0.99)$ & $-0.13(0.99)$ & $-0.18(0.99)$ & $0.02^{\mathrm{a}}$ \\
\hline Waist circumference, $\mathrm{cm}^{\mathrm{e}}$ & $64.2(7.8)$ & $63.2(7.4)$ & $65.3(8.0)$ & $<0.001^{\mathrm{a}}$ \\
\hline $\mathrm{WH}_{\mathrm{tR}}^{\mathrm{e}}$ & $0.43(0.05)$ & $0.43(0.04)$ & $0.44(0.05)$ & $<0.001^{\mathrm{a}}$ \\
\hline \multicolumn{5}{|l|}{ Central obesity ${ }^{\mathrm{e}}$} \\
\hline Yes, $n(\%)$ & $925(8.7)$ & $397(7.1)$ & $528(10.5)$ & $<0.001^{f}$ \\
\hline No, $n(\%)$ & $9,697(91.3)$ & $5,182(92.9)$ & $4,515(89.5)$ & \\
\hline
\end{tabular}

${ }^{a}$ Results from the independent samples $t$ test. ${ }^{b}$ IOTF [2, 3]. ${ }^{c}$ WHO [4]. ${ }^{d}$ FIN [7]. ${ }^{e}$ Girls: $n=5,579 ;$ boys: $n=5,043$. ${ }^{f}$ Results from Pearson's $X^{2}$ test.

children's age and sex were confirmed through linkage to the National Population Information System at the Population Register Center.

\section{Anthropometric Measures}

In schools, trained fieldworkers weighed the children and measured their height and waist circumference following a standardized protocol as described elsewhere [30]. The children wore indoor clothes, the weight of which was subtracted from the measured weight. Approximately 13\% of children participated from home, receiving a measuring tape and detailed written instructions for reporting their body measurements with an adult's assistance. We previously established that the self-reported measurements were valid [31]. BMI (weight $[\mathrm{kg}] /$ height $[\mathrm{m}]^{2}$ ) and the WHtR (waist $[\mathrm{cm}] /$ height $[\mathrm{cm}]$ ) were calculated. Using a WHtR cutoff of 0.5 indicated central obesity $[24,32]$.

Cutoff Values for Thinness, Overweight, and Obesity Based on IOTF, WHO, and FIN Reference Values

IOTF, WHO, and FIN growth references were used to calculate the $z$-scores for BMI-for-age, which were classified as thinness, normal weight, overweight, and obesity using established cutoff values $[2-4,7]$. In summary, the IOTF BMI $z$-score thresholds for thinness, overweight, and obesity were $-1.014,1.310$, and 2.288 for boys and $-0.975,1.244$, and 2.192 for girls [3], whereas WHO's cutoff values for thinness, overweight, and obesity were $-2,1$, and 2, respectively, for both sexes [4]. The FIN growth reference cutoff values were approximately -1.834 and -1.648 for thinness, 0.778 and 1.163 for overweight, and 1.702 and 2.107 for obesity in boys and girls, respectively [7].

\section{Statistical Analyses}

The general characteristics of the study population are reported as means (standard deviations [SD]) or as numbers and percentages. The comparison of characteristics between two groups was performed using the independent samples $t$ test for continuous variables and using the $\chi^{2}$ test for categorical variables. Distributions of weight status using the three reference systems were compared between sexes using the $\chi^{2}$ test. The kappa coefficient assessed the degree of agreement across the reference systems: (1) IOTF versus WHO, (2) IOTF versus FIN, and (3) WHO versus FIN. Agreement was characterized as suggested by Landis and Koch [33]. The percentage of agreement was calculated using cross-tabulations.

Sensitivity and specificity were used as measures for the agreement of central obesity with overweight and obesity. Sensitivity, or a true positive rate, was calculated by dividing the number of children with either overweight or obesity and the WHtR $>0.5$ by the number of all children with a WHtR $>0.5$. Specificity, or a true negative rate, was calculated by dividing the number of children with either thinness or a normal weight and $\mathrm{WHtR} \leq 0.5$ by all children with a WHtR $\leq 0.5$.

Data on waist circumference were missing for 24 children. We considered $p<0.05$ as statistically significant. All statistical analyses were performed using the software package IBM SPSS Statistics version 24.0 (IBM SPSS Statistics, Armonk, NY, USA).

\section{Results}

The study population included a total of 10,646 children, of whom $52.5 \%$ were girls (Table 1 ). The mean age, height, weight, and BMI did not differ based on sex. The mean BMI $z$-scores however differed between the sexes across all reference systems: boys exhibited higher mean BMI $z$-scores than girls using IOTF and WHO, while these were lower using the FIN reference system. The mean BMI $z$-score using FIN was -0.16 (SD 0.99). Thus, the mean BMI $z$-score in Fin-HIT participants was 0.16 
Fig. 1. Prevalence of thinness, normal weight, overweight, and obesity among all children $(n=10,646)$ and separately among girls $(n=5,594)$ and boys $(n=5,052)$ according to the different reference values. ${ }^{\mathrm{a} C}$ Comparison between sexes, results from Pearson's $\chi^{2}$ test. ${ }^{b}$ IOTF $[2,3] .{ }^{c}$ WHO [4]. dFIN [7].

Table 2. Agreement between weight status reported as the kappa coefficient $(\mathrm{K})$ and $95 \%$ confidence interval across the three reference systems

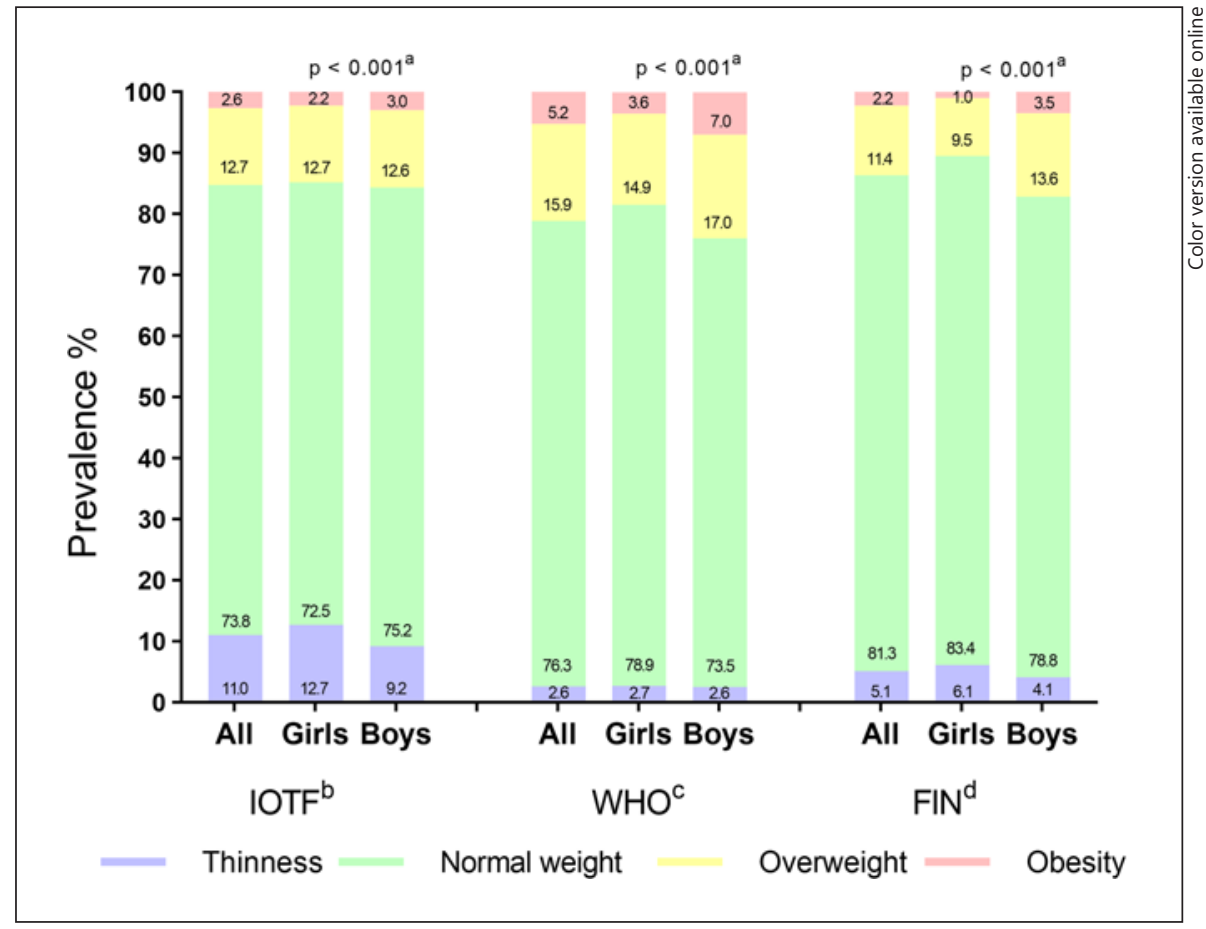

\begin{tabular}{llll}
\hline & All $(n=10,646)$ & Girls $(n=5,594)$ & Boys $(n=5,052)$ \\
\hline IOTF $^{\mathrm{a}}$ versus WHO & $0.59(0.58-0.61)$ & $0.63(0.61-0.65)$ & $0.55(0.53-0.57)$ \\
IOTF $^{\mathrm{b}}$ versus FINc & $0.74(0.73-0.76)$ & $0.68(0.65-0.70)$ & $0.82(0.80-0.83)$ \\
WHO $^{\mathrm{b}}$ versus FINc & $0.64(0.62-0.65)$ & $0.57(0.55-0.60)$ & $0.70(0.68-0.72)$ \\
\hline
\end{tabular}

a IOTF [2, 3]. ${ }^{\mathrm{b}}$ WHO [4]. ${ }^{\mathrm{C}}$ FIN [7].

\begin{tabular}{llll}
\hline Weight status & IOTF $^{\mathrm{a}}$ and WHO & IOTF $^{\mathrm{a}}$ and FIN & WHOb and FINc \\
\hline Thinness, $n$ & 280 & 548 & 280 \\
Normal weight, $n$ & 7,229 & 7,779 & 7,856 \\
Overweight, $n$ & 1,064 & 1,071 & 895 \\
Obesity, $n$ & 274 & 205 & 233 \\
Total in agreement, $n(\%)$ & $\mathbf{8 , 8 4 7}(\mathbf{8 3 . 1})$ & $\mathbf{9 , 6 0 3 ( 9 0 . 2 )}$ & $\mathbf{9 , 2 6 4 ( 8 7 . 0 )}$ \\
Total in nonagreement, $n(\%)$ & $1,799(16.9)$ & $1,043(9.8)$ & $1,382(13.0)$ \\
\hline
\end{tabular}

${ }^{\mathrm{a}}$ IOTF $[2,3] .{ }^{\mathrm{b}} \mathrm{WHO}[4] .{ }^{\mathrm{c}} \mathrm{FIN}[7]$.
Table 3. Number of children having the same weight status within IOTF and $\mathrm{WHO}$ IOTF and FIN; and WHO and FIN reference systems $(n=10,646)$
SD lower than in the nationally representative FIN reference data. Waist circumference and the WHtR were larger among boys than girls. In addition, the prevalence of central obesity was $8.7 \%$ and was more common in boys than in girls $(10.7 \%$ vs. $7.1 \%, p<0.001$; Table 1$)$.

The prevalence of thinness, overweight, and obesity were $11.0 \%, 12.7 \%$, and $2.6 \%$, respectively, using IOTF; $2.6 \%, 15.9 \%$, and $5.2 \%$ using WHO; and $5.1 \%, 11.4 \%$, and
2.2\% using FIN (shown in Fig. 1). Based on WHO and FIN, we observed a higher proportion of boys with overweight or obesity than girls, while this did not emerge using IOTF. Thinness appeared more common in girls than boys using IOTF and FIN.

IOTF showed only a moderate agreement with WHO $(\kappa=0.59$; Table 2$) ; 83 \%$ of children had the same weight status with both reference systems (Table 3 ). This agree- 
Table 4. The Fin-HIT cohort: proportion of children with either thinness/normal weight or overweight/obesity without (WHtR $\leq 0.5)$ and with central obesity $(\mathrm{WHtR}>0.5)$ according to the three reference systems

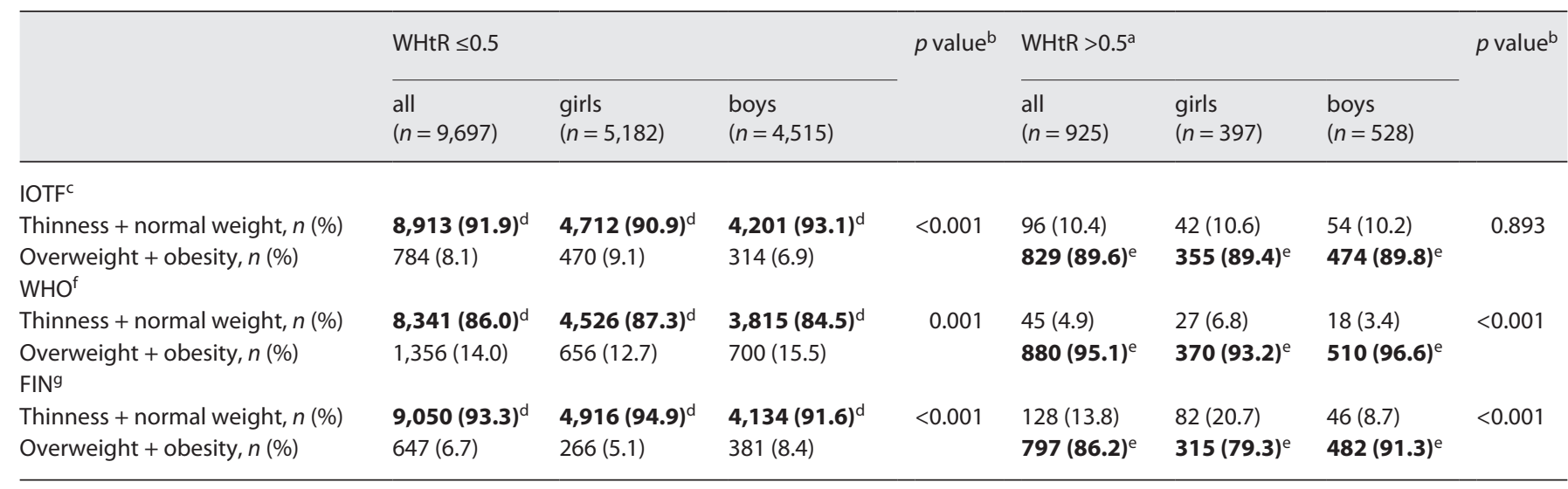

Shown for all children ( $n=10,622 ; 24$ missing values) and separately for girls ( $n=5,579 ; 15$ missing values) and boys ( $n=5,043 ; 9$ missing values). ${ }^{\text {a }}$ in the WHtR $>0.5$ group, no individuals fell into the thinness category. ${ }^{b}$ Comparison between sexes, results from Pearson's $X^{2}$ test. ${ }^{~}$ IOTF [2, 3]. ${ }^{\mathrm{d}}$ Specificity (percentage in bold): the number of children with thinness or a normal weight and a WHtR $\leq 0.5$ divided by the total number of children with a WHtR $\leq 0.5$. e Sensitivity (percentage in bold): the number of children with overweight or obesity and WHtR $>0.5$ divided by the total number of children with a WHtR $>0.5 .{ }^{f}$ WHO [4]. ${ }^{\mathrm{g}} \mathrm{FIN}[7]$.

ment was slightly enhanced using WHO and FIN $(\kappa=$ $0.64 ; 87 \%$ agreement) and even better between IOTF and FIN ( $\kappa=0.74 ; 90 \%$ agreement). Among those classified as overweight using WHO, $37 \%$ and $47 \%$, respectively, were regarded as normal weight according to IOTF and FIN. A higher agreement was observed for boys than girls using IOTF versus FIN and WHO versus FIN, while IOTF versus WHO showed an opposing sex difference (Table 2).

WHO exhibited the highest agreement with central obesity, that is, the highest sensitivity: $95 \%$ of those with a WHtR $>0.5$ were classified as with overweight or obesity (Table 4). For IOTF and FIN, the corresponding percentages were $90 \%$ and $86 \%$, respectively. The lowest sensitivity was observed among girls using FIN (79\%). The results for specificity - that is, the proportion of children with a WHtR $\leq 0.5$ classified with thinness or normal weight - were 93\% (FIN), 92\% (IOTF), and 86\% (WHO).

\section{Discussion}

\section{Key Findings and Novelty of the Study}

To our knowledge, this is the first study to compare the prevalence of thinness, normal weight, overweight, and obesity among children using IOTF, WHO, and the FIN BMI-for-age reference values. This is also the first study to monitor the performance of these reference systems against an external measure, in this case, central obesity. We compared the three reference systems in an equal manner without highlighting any of them because they are suitable for different purposes.

We found that the prevalence of thinness, overweight, and obesity in a representative sample of Finnish children depends on the reference system applied. The combined prevalence of overweight and obesity varied from 13.6\% to $21.1 \%$, with FIN exhibiting the lowest and WHO the highest prevalence. Yet, IOTF yielded the highest prevalence of thinness (11.0\%), a rate four times higher than that using WHO and twice as high as when using FIN. In general, the strongest agreement between reference systems was found when comparing IOTF and FIN. WHO showed the highest sensitivity with non-BMI-related central obesity, while the highest specificity was achieved using FIN.

\section{Agreement between Reference Systems}

In our previous studies $[30,34,35]$, we used the IOTF reference system since it is preferred in international comparisons [3]. Here, we observed substantial agreement with FIN but only moderate agreement with WHO. Compared with IOTF, WHO both underestimates the proportion of thinness and overestimates the prevalence of overweight (including obesity). Our results agree with previous studies, showing a higher prevalence of overweight and obesity among children when using WHO than when using IOTF [3, 8-19]. Possible explanations 
for the difference between IOTF and WHO lie in the different populations, time periods, and methodologies studied, all of which affect the cutoff values [36]. The main difference between IOTF and FIN however arises from categorizing the lowest BMI values, while only minor differences appear regarding overweight and obesity for the entire cohort. Furthermore, IOTF has received criticism for relying on too broad of a definition for the lowest category - that is, for including all BMIs passing through 18.5 or below at the age of 18 years $[7,37]$. However, this category is labeled thinness to distinguish it from being underweight [3].

\section{Sex Differences}

Except for IOTF, the reference systems revealed that school-aged boys had a higher prevalence of overweight and obesity than girls. A higher prevalence of overweight and obesity among boys at this age seems more common globally [1] as well as among Finnish children [38]. In a European study in eight countries, a higher proportion of boys than girls was classified as at least overweight according to $\mathrm{WHO}$, whereas overweight and obesity were more prevalent among girls than boys when using IOTF [8]. Similar findings were reported in a French study [9], while a Swedish study found no statistically significant differences between the sexes [10]. Furthermore, agreement across reference systems depends on sex. Accordingly, we observed the poorest agreement between IOTF and WHO in boys, while the strongest agreement appeared using IOTF and FIN in boys.

Several reasons may explain the higher prevalence of overweight and obesity in preadolescent boys compared with girls. Since a higher prevalence of overweight and obesity is observed particularly among preschool-age girls across Europe [8], it is tempting to assume that the timing of pubertal growth may alter the situation. Sex differences may also relate to lifestyle and other factors [39]. Previously, we showed that unhealthy eating habits were more common [40], and the frequency of consuming sweet treats was higher [34] in boys than in girls. However, boys are generally more physically active than girls [41], which complicates explanations.

\section{Central Obesity}

The rate of central obesity was $8.7 \%$ in our sample, a level similar to that in Norway [42] and Poland [43], while considerably lower than reports among children in Greece (33\%) [44], Australia (23\%) [45], or Italy (13\%) [46]. The novelty of our study was that we examined agreement between the weight status defined using differ-

Comparison of Reference Values for BMI-

for-Age ent reference systems with central obesity based on the WHtR. WHO showed the highest sensitivity (95\%) with central obesity, while the FIN reference yielded the highest specificity (93\%). However, the overall differences in sensitivity and specificity between the reference systems remained small and again depended on sex: across all reference systems, sensitivity was higher in boys than girls. The results for sensitivity appear related to the overall percentage of overweight and obesity. Sex differences might be explained by the fact that overweight and obesity more commonly occurred in boys, while thinness and being normal weight were more common in girls.

\section{Strength and Limitations of the Study}

A major strength of our study stems from the large sample size of school-aged children from six densely populated areas of Finland. In addition, weight, height, and waist circumference were measured and not self-reported among most of the children in our study. The children were between 9 and 12 years old, given that our focus was on preadolescence. One limitation to this study is that we did not include the pubertal stage in our analysis, although this would have proved informative. At this age, the sexual maturation of boys and girls naturally differs [47]: some girls might be at the mid- to postpubertal stage, while the majority of boys are still at the prepubertal stage, possibly impacting our results.

\section{Conclusions}

The combined prevalence of overweight and obesity varied from $13.6 \%$ to $21.1 \%$, depending upon the reference system applied. Although prevalence varied in our sample using the three reference systems, their impact on the association of interest requires verification through future studies. Presumably with a higher frequency of overweight and obesity, a stronger association may be observed. Nonetheless, weight status falls into four categories, the use of which rather than a dichotomized variable remains an objective means of performing such analyses.

Our results suggest that future studies should use the IOTF reference system allowing for international comparisons, although it might be necessary to limit the lowest BMI category to only those with grade 2 (BMI 17) and 3 (BMI 16) thinness in order to avoid overreporting thinness, which is further supported by the FIN reference system. In addition, we recommend using the WHtR alongside BMI since it illustrates pathological fat accumulation along the central body [32]. Furthermore, the WHtR is 
relevant when studying weight-related behaviors, such as screen time [35] and sweet treat consumption [34].

Monitoring prevalence and identifying effective prevention strategies for obesity remains the highest priority in order to tackle the global obesity epidemic. However, caution is required when comparing prevalence rates of overweight and obesity across studies which use different reference systems.

\section{Statement of Ethics}

The Coordinating Ethics Committee of the Hospital District of Helsinki and Uusimaa approved the study protocol $(169 / 13 / 03 / 00 / 10)$. Each child and one of their guardians provided informed written consent prior to participation in the study.

\section{Conflict of Interest Statement}

The authors have no conflicts of interest to declare.

\section{Funding Sources}

The Fin-HIT study is supported by the Folkhälsan Research Foundation, the Academy of Finland, "Medicinska Understödsföreningen Liv och Hälsa", the Swedish Cultural Foundation in Finland, the Finnish Cultural Foundation, the Signe and Ane Gyllenberg Foundation, and the Päivikki and Sakari Sohlberg Foundation.

\section{Author Contributions}

C.S. was involved in data collection; carried out the literature search; performed the data analyses with assistance from J.V., R.A.O.F., and H.V.; and drafted the manuscript. All the authors contributed to study design, participated in data interpretation, revised the manuscript, and accepted the final manuscript for submission.

\section{Data Availability Statement}

The Fin-HIT study welcomes collaborative research partners. Requests can be sent to the corresponding author, principal investigator Heli Viljakainen.

\section{References}

1 Bentham J, Di Cesare M, Bilano V, Bixby H, Zhou B, Stevens GA, et al. Worldwide trends in body-mass index, underweight, overweight, and obesity from 1975 to 2016: a pooled analysis of 2416 population-based measurement studies in 128.9 million children, adolescents, and adults. Lancet. 2017; 390(10113):2627-42.

2 Cole TJ, Bellizzi MC, Flegal KM, Dietz WH. Establishing a standard definition for child overweight and obesity worldwide: international survey. BMJ. 2000;320(7244): 1240-3.

3 Cole TJ, Lobstein T. Extended international (IOTF) body mass index cut-offs for thinness, overweight and obesity. Pediatr Obes. 2012; 7(4):284-94.

4 de Onis M, Onyango AW, Borghi E, Siyam A, Nishida C, Siekmann J. Development of a WHO growth reference for school-aged children and adolescents. Bull World Health Organ. 2007;85(9):660-7.

5 World Health Organization. Physical status: the use and interpretation of anthropometry. Technical report series. 1995; 1-454.

6 WHO Multicentre Growth Reference Study Group. WHO Child Growth Standards based on length/height, weight and age. Acta Paediatr Suppl. 2006;450:76-85.

7 Saari A, Sankilampi U, Hannila ML, Kiviniemi V, Kesseli K, Dunkel L. New Finnish growth references for children and adolescents aged 0 to 20 years: length/height-for- age, weight-for-length/height, and body mass index-for-age. Ann Med. 2011;43(3):235-48.

8 Ahrens W, Pigeot I, Pohlabeln H, De Henauw S, Lissner L, Molnár D, et al. Prevalence of overweight and obesity in European children below the age of 10. Int J Obes. 2014;38(Suppl 2):S99-107.

9 Kêkê LM, Samouda H, Jacobs J, di Pompeo C, Lemdani $\mathrm{M}$, Hubert $\mathrm{H}$, et al. Body mass index and childhood obesity classification systems: a comparison of the French, International Obesity Task Force (IOTF) and World Health Organization (WHO) references. Rev Epidemiol Sante Publique. 2015;63(3):173-82.

10 Nilsen BB, Yngve A, Sjöberg A, Moraeus L, Lissner L, Werner B. Using different growth references to measure thinness and overweight among Swedish primary school children showed considerable variations. Acta Paediatr. 2016;105(10):1158-65.

11 Minghelli B, Nunes C, Oliveira R. Body mass index and waist circumference to define thinness, overweight and obesity in portuguese adolescents - comparison between CDC, IOTF WHO references. Pediatr Endocrinol Rev. 2014;12(1):35-41.

12 Kovacs VA, Bakacs M, Kaposvari C, Illes E, Erdei G, Martos E, et al. Weight status of 7-year-old Hungarian children between 2010 and 2016 using different classifications (COSI Hungary). Obes Facts. 2018;11(3):195-205.

13 Dereń K, Nyankovskyy S, Nyankovska O, Łuszczki E, Wyszyńska J, Sobolewski M, et al.
The prevalence of underweight, overweight and obesity in children and adolescents from Ukraine. Sci Rep. 2018;8(1):3625.

14 López-Sánchez GF, Sgroi M, D’Ottavio S, Díaz-Suárez A, González-Víllora S, Veronese $\mathrm{N}$, et al. Body composition in children and adolescents residing in southern Europe: prevalence of overweight and obesity according to different international references. Front Physiol. 2019;10:130.

15 Gama A, Rosado-Marques V, Machado-Rodrigues AM, Nogueira H, MourÃo I, Padez C. Prevalence of overweight and obesity in 3-to10-year-old children: assessment of different cut-off criteria WHO-IOTF. An Acad Bras Cienc. 2020;92(2):e20190449.

16 Chirita-Emandi A, Barbu CG, Cinteza EE Chesaru BI, Gafencu M, Mocanu V, et al. Overweight and underweight prevalence trends in children from Romania: pooled analysis of cross-sectional studies between 2006 and 2015. Obes Facts. 2016;9(3):20620.

17 Gonzalez-Casanova I, Sarmiento OL, Gazmararian JA, Cunningham SA, Martorell R, Pratt $\mathrm{M}$, et al. Comparing three body mass index classification systems to assess overweight and obesity in children and adolescents. Rev Panam Salud Publica. 2013;33(5):349-55.

18 Pelegrini A, Silva DA, Gaya AC, Petroski EL Comparison of three criteria for overweight and obesity classification in Brazilian adolescents. Nutr J. 2013;12:5. 
19 Wamba PC, Enyong Oben J, Cianflone K. Prevalence of overweight, obesity, and thinness in cameroon urban children and adolescents. J Obes. 2013;2013:737592.

20 Bahreini N, Noor MI, Koon PB, Talib RA, Lubis SH, Ganjali Dashti M, et al. Weight status among Iranian adolescents: comparison of four different criteria. J Res Med Sci. 2013; 18(8):641-6.

21 Salehi-Abargouei A, Abdollahzad H, Bameri Z, Esmaillzadeh A. Underweight, overweight and obesity among Zaboli adolescents: a comparison between international and Iranians' national criteria. Int J Prev Med. 2013;4(5): 523-30.

22 Yang L, Bovet P, Ma C, Zhao M, Liang Y, Xi $B$. Prevalence of underweight and overweight among young adolescents aged $12-15$ years in 58 low-income and middle-income countries. Pediatr Obes. 2019;14(3):e12468.

23 Moraeus L, Lissner L, Sjöberg A. Stable prevalence of obesity in Swedish schoolchildren from 2008 to 2013 but widening socio-economic gap in girls. Acta Paediatr. 2014; 103(12):1277-84.

24 Savva SC, Tornaritis M, Savva ME, Kourides Y, Panagi A, Silikiotou N, et al. Waist circumference and waist-to-height ratio are better predictors of cardiovascular disease risk factors in children than body mass index. Int $\mathrm{J}$ Obes. 2000;24(11):1453-8.

25 Martin-Calvo N, Moreno-Galarraga L, Martinez-Gonzalez M. Association between body mass index, waist-to-height ratio and adiposity in children: a systematic review and metaanalysis. Nutrients. 2016;8(8):512.

26 Yoo EG. Waist-to-height ratio as a screening tool for obesity and cardiometabolic risk. Korean J Pediatr. 2016;59(11):425-31.

27 Ashwell M, Hsieh SD. Six reasons why the waist-to-height ratio is a rapid and effective global indicator for health risks of obesity and how its use could simplify the international public health message on obesity. Int J Food Sci Nutr. 2005;56(5):303-7.
28 McCarthy HD, Ashwell M. A study of central fatness using waist-to-height ratios in UK children and adolescents over two decades supports the simple message: "keep your waist circumference to less than half your height". Int J Obes. 2006;30(6):988-92.

29 Kromeyer-Hauschild K, Neuhauser H, Schaffrath Rosario A, Schienkiewitz A. Abdominal obesity in german adolescents defined by waist-to-height ratio and its association to elevated blood pressure: the KiGGS study. Obes Facts. 2013;6(2):165-75

30 Figueiredo RAO, Simola-Ström S, Rounge TB, Viljakainen H, Eriksson JG, Roos E, et al. Cohort profile: the Finnish Health in Teens (Fin-HIT) study - a population-based study. Int J Epidemiol. 2019;48(1):22-4h.

31 Sarkkola C, Rounge TB, Simola-Ström S, von Kraemer S, Roos E, Weiderpass E. Validity of home-measured height, weight and waist circumference among adolescents. Eur J Public Health. 2016;26(6):975-7.

32 Lo K, Wong M, Khalechelvam P, Tam W. Waist-to-height ratio, body mass index and waist circumference for screening paediatric cardio-metabolic risk factors: a meta-analysis. Obes Rev. 2016;17(12):1258-75.

33 Landis JR, Koch GG. The measurement of observer agreement for categorical data. Biometrics. 1977;33(1):159.

34 Lommi S, Engberg E, Tuorila H, Kolho K-L, Viljakainen H. Sex-and weight-specific changes in the frequency of sweet treat consumption during early adolescence: a longitudinal study. Br J Nutr. 2021;126(10):1592600.

35 Engberg E, Figueiredo RAO, Rounge TB, Weiderpass E, Viljakainen H. Heavy screen users are the heaviest among 10,000 children. Sci Rep. 2019;9(1):11158.

36 Neovius M, Linné Y, Barkeling B, Rössner S. Discrepancies between classification systems of childhood obesity. Obes Rev. 2004;5(2): 105-14.

37 Chinn S, Rona RJ. International definitions of overweight and obesity for children: a lasting solution? Ann Hum Biol. 2002;29(3):306-13.
38 Mäki P, Lehtinen-Jacks S, Vuorela N, Levälahti E, Koskela T, Saari A, et al. Register of primary health care visits (Avohilmo) as data source for monitoring the prevalence of overweight among Finnish children. (In Finnish with an English summary). Suom Lääkäril. 2017;4:209-15.

39 Greco E, Meo F, Cedrone F. Gender differences in childhood BMI z-score, alimentary behaviour and lifestyle in a sample of 9-11 children. Clin Ter. 2020;171(5):e425-30.

40 de Oliveira Figueiredo RA, Viljakainen J, Viljakainen $\mathrm{H}$, Roos E, Rounge TB, Weiderpass E. Identifying eating habits in Finnish children: a cross-sectional study. BMC Public Health. 2019;19(1):312.

41 Rosenfeld CS. Sex-dependent differences in voluntary physical activity. J Neurosci Res. 2017;95(1-2):279-90.

42 Fredriksen PM, Skår A, Mamen A. Waist circumference in 6-12-year-old children: the Health Oriented Pedagogical Project (HOPP). Scand J Public Health. 2018;46(21_Suppl): 12-20.

43 Nawarycz T, So HK, Choi KC, Sung RYT, Li AM, Nelson EAS, et al. Waist-to-height ratio as a measure of abdominal obesity in southern Chinese and European children and adolescents. Int J Obes. 2016;40(7):1109-18.

44 Grigorakis DA, Georgoulis M, Psarra G, Tambalis KD, Panagiotakos DB, Sidossis LS. Prevalence and lifestyle determinants of central obesity in children. Eur J Nutr. 2016; 55(5):1923-31.

45 Hardy LL, Xu J, Guo CZ, Garnett SP. 30-year cross-sectional trends in waist-to-height ratio in Australian school age children; 1985 to 2015. Acta Paediatr. 2019;108(4):707-11.

46 Santomauro F, Lorini C, Pieralli F, Niccolai G, Picciolli P, Vezzosi S, et al. Waist-to-height ratio and its associations with body mass index in a sample of Tuscan children in primary school. Ital J Pediatr. 2017;43(1):53.

47 Alotaibi MF. Physiology of puberty in boys and girls and pathological disorders affecting its onset. J Adolesc. 2019;71:63-71. 